\section{Intracranial metallic foreign bodies in a man with a headache}

\author{
Zerrin Pelin, ${ }^{1}$ Tuncay Kaner² \\ 1Erenköy Psychiatry and Neurology, \\ Education and Research Hospital, \\ Department of Neurology, Istanbul; \\ 2Istanbul Medeniyet University School \\ of Medicine, Department \\ of Neurosurgery, Istanbul, Turkey
}

\section{Abstract}

We report the case of a 22-year old man with intracranial metallic foreign bodies who presented complaining of a headache. His history of headaches had begun when he was five years old and continued with increasing severity. Six months before hospital admission, nausea and vomiting began to accompany his headache. Computed tomography scan revealed that 2 metallic foreign bodies were located adjacent to the vertex and another was next to the ambient cistern. The location and position of foreign bodies suggested that they were introduced in infancy through the anterior fontanelle before its closure in an unsuccessful homicide attempt. This case is one of the few reported cases combining headache and intracranial foreign bodies and we discuss the relationship between headache and these metallic materials.

\section{Introduction}

Intracranial foreign bodies are generally due to penetrating injuries through the orbit, ear or cranial bones. ${ }^{1-3}$ Penetrating trauma secondary to gunshot wounds are a common cause of injury. However, penetrating cranio-cerebral injuries due to objects such as needles, iron rods, pieces of wood or nails are rare. ${ }^{4}$

It is rare to discover a foreign body which has been inserted through either of the fontanelles before their closure in an attempted infanticide. ${ }^{5-7}$ Such foreign bodies are usually detected accidentally, most often after minor head injury necessitating plain cranial radiography. 6 There are only a few patients in the literature who present with headache or seizures who have intracranial foreign bodies. In this case, we report a patient with 3 intracranial metallic foreign bodies who suffered from headaches.

\section{Case Report}

A 22-year old man, who was employed as a construction worker, presented with a history of chronic headaches. He was from a small village in eastern Turkey and he is the third of 8 children. His headaches had begun when he was five years old. During his childhood, diffuse pain involving posterior aspects of the head and periorbital area occurred regularly, especially when he was concentrating on something in particular. He denied any hospitalizations during childhood due to his family's poor socio-economic status. When he was 20 years old, the frequency and intensity of his headaches began to increase. The headache recurred every day and lasted for more than four hours. During episodes of headache, the most uncomfortable area was the periorbital areas. Although non-steroidal anti-inflammatory drugs, such as naproxen sodium, diclofenac sodium and ibuprofen, were given to the patient, they did not supply permanent analgesia. Six months before admission to our clinic, his headache took on a pulsating quality accompanied with nausea and vomiting.

On admission, his general physical status was found to be normal. He was conscious, alert and cooperative. He did not have any physical signs of injury. The patient had no evidence of intellectual problems, delayed growth or mental retardation. Neurological examination did not show any abnormalities.

Cranial radiography detected what appeared to be foreign bodies adjacent to the vertex region (Figure 1). Three dimensional cranial computed tomography (CT) was performed to further evaluate the presence of the foreign objects in the cranium. A CT scan showed 2 metallic foreign bodies adjacent to the vertex and one adjacent to the ambient cistern (Figures 2 and 3 ).

The patient and his relatives stated that they did not know how these metallic bodies had been introduced. The positions of the foreign bodies, however, suggested that they were probably inserted through the anterior fontanelle when the patient was an infant.

Surgical intervention was considered unnecessary and potentially hazardous to the patient, and the metallic foreign bodies in his cranium were accepted as an incidental finding. He was discharged from the hospital with analgesic medications and was informed about the contraindications for magnetic resonance imaging.

\section{Discussion}

We report a case of a possible association
Correspondence: Tuncay Kaner, Istanbu Medeniyet University School of Medicine, Department of Neurosurgery, Istanbul, Turkey.

Tel. +90.532 .2627715 .

E-mail: tuncaykaner@gmail.com

Key words: brain, foreign body, sewing needle, homicide, headache.

Conflict of interests: the authors report no potential conflict of interests.

Received for publication: 29 July 2012 .

Revision received: 23 August 2012.

Accepted for publication: 2 October 2012

This work is licensed under a Creative Commons Attribution NonCommercial 3.0 License (CC BYNC 3.0).

(C) Copyright Z. Pelin and T. Kaner, 2012 Licensee PAGEPress, Italy

Neurology International 2012; 4:e18

doi:10.4081/ni.2012.e18

between intracranial needles and headaches. There are previously reported cases of sewing needles and other foreign objects retained in the brain for long periods of time without any symptoms. In our case, the intracranial needles were detected after a long period of time. During that period, the intensity, duration and localization of the headache altered as did the accompanying symptoms. All other reported cases except one describe single intracranial metallic objects. The radiological findings in our patients strongly suggest that three needles had been introduced into the brain.

A variety of penetrating objects of the skull and brain have been reported, including blades, nails, pencils, splinters of wood and wire. ${ }^{4}$ Intracranial foreign bodies are usually due to penetrating injuries through the cranial bones, orbits and ear.1-3 Intracranial sewing needles have been previously reported in the literature..$^{5-9}$ It has also been reported that surgical objects may be left in the brain during surgery. 10 The radiological findings in our patient demonstrated that intracranial foreign bodies resembled sewing needles. The locations of these objects suggested that intracranial needles might have been inserted through the cranium during infancy before the closure of the fontanelle. The intracranial location of the sewing needles are thought to be the result of an unsuccessful infanticide attempt or of an accident during infancy.7,11 Amirjamshidi et al. suggested that this is a kind of so called battered child syndrome phenomenon which might have been traditional and prevalent in some communities. ${ }^{12}$ This kind of accident might also have been due to another child poking a baby with a couple of needles, or the child could have done it him- 


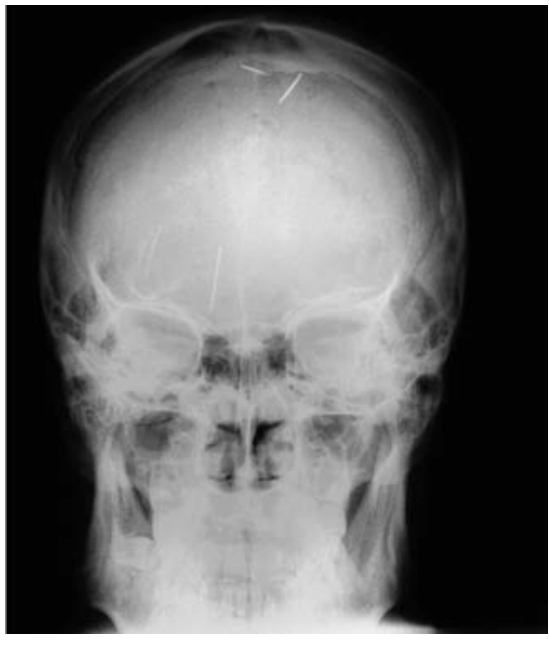

Figure 1. Plain X-ray of the patient.

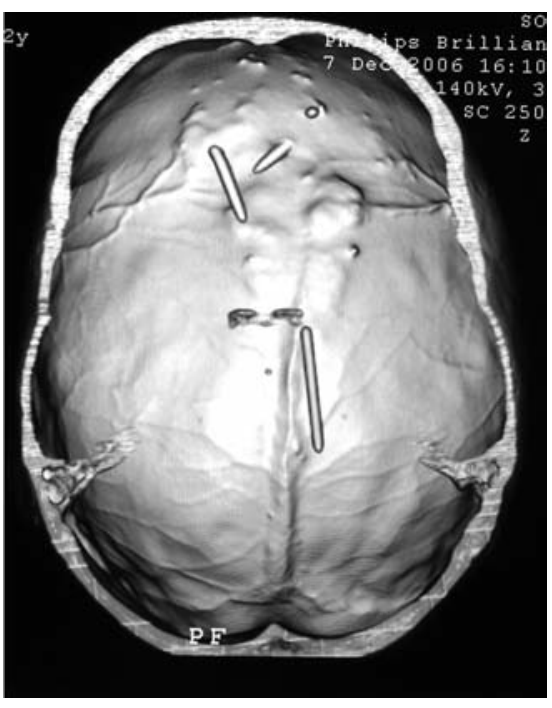

Figure 2. Three dimensional brain tomography showing the position of the 3 needles.

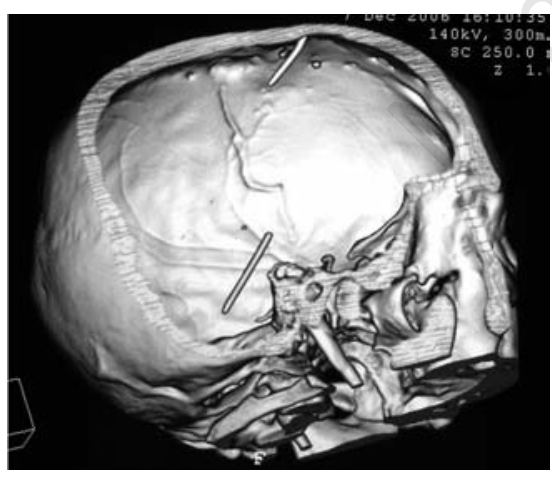

Figure 3. Three dimensional brain tomography showing the position of the 3 needles. self, and can not remember the event as an adult.

In clinical practice, many physicians prefer magnetic resonance imaging (MRI) to evaluate intractable headache. It might be possible to see cases like that of our patient especially in developing countries and MRI could have disastrous consequences. Therefore, it becomes more important to make a gradual evaluation of pain step by step and an MRI should not be ordered immediately. The problem of headache in similar cases is not usually clear. Some authors have suggested that the biochemical composition of the iron rust surrounding the sewing needles in the brain may be a cause of headache. ${ }^{13}$

There is no consensus on whether the retained needles should be removed surgically or not, and this issue has been the subject of controversy in other reports.5,6 Surgical interventions were reported in medulla oblongata lesions by needles in several cases.14-16 In one case, extirpation of the needle using a magnet proved useful. ${ }^{4}$ In another case, suboccipital craniotomy was performed without using electrocauterization and the needle was withdrawn using a string. 16 In the present case, surgical intervention was not considered for two reasons: i) the needles were evaluated as an incidental finding to the principle complaint of headaches; and ii) potential surgical damage could worsen the patient's quality of life.

\section{Conclusions}

Although the prevalence of cases of intracranial sewing needles is not common in the literature, this may be due to the low associated survival rate. Surviving cases are mostly diagnosed by skull radiography after minor head injury.6,8 In our case, intracranial needles were found to be an incidental finding during evaluation of a patient for headache. The discovery of 3 inserted needles was thought to be an interesting finding for the literature.

\section{References}

1. Jinkins JR, Dadsetan MR, Sener RN, et al. Value of acute-phase angiography in the detection of vascular injuries caused by gunshot wounds to the head. Analysis of 12 cases. AJR 1992;15:365-8.

2. Kuroiwa T, Tanabe H, Ogawa D, Ohta T. Chopstich penetration of the posterior cranial fossa: case report. Surg Neurol 1995;43:68-9.

3. Sener RN. Intracranial sewing needles in a 20-year-old patient. J Neuroradiol 1997;24:212-4.

4. Ashkenazi E, Mualem N, Umansky F. Successful removal of an intracranial needle by an ophthalmologic magnet: case report. J Trauma 1990;30:114-5.

5. Barlas 0, Gökay H. Sewing needles in the brain. Neurosurgery 1983;13:105-6.

6. Rahimizadeh A, Sabouri-Daylami M, Tabatabi M, et al. Intracranial sewing needles. Neurosurgery 1987;20:666.

7. Azariah RG. An unusual metallic foreign body in the brain. Case report. J Neurosurg 1970;32:95-9.

8. Unal N, Babayigit A, Karababa S, Yilmaz S. Asymptomatic intracranial sewing needle: an unsuccessful infanticide attempt? Pediatr Int 2005;47:206-8.

9. Amirjamshidi A, Ghasvini AR, Alimohammadi $\mathrm{M}$, et al. Attempting homicide by inserting sewing needle into the brain. Report of 6 cases and review of literature. Surg Neurol 2009;6;635-41.

10. Askenasy HM, Kosary IZ, Braham J. Sewing needles in the brain with delayed neurological manifestation. J Neurosurg 1961;18:554-6.

11. Tuncer N, Yaycı N, Ekinci G, et al. Intracranial sewing needle in a man with seizure: a case of child abuse? Forensic Sci Int 2007;24;168:212-4.

12. Amirjamshidi A, Abbassioun K, Amirjamshidi G. That is why people are frightened of needles! Childs Nerv Syst 2009;25:9078.

13. Sturiale CL, Massimi L, Mangiola A, et al. Sewing needles in the brain: infanticide attempts or accidental insertion? Neurosurgery 2010;67:E1170-9.

14. Abumi K, Anbo H, Kaneda K. Migration of an acupuncture needle in to the medulla oblongata. Eur Spine J 1999;5:137-9.

15. Hama Y, Kaji T. A migrated acupuncture needle in the medulla oblongata. Arch Neurol 2004;61:1608.

16. Takayashi K, Morimura N, Sakamoto T, et al. Medullar injury caused by sewing needle puncture. J Emerg Med 2011;40:65-7. 